\title{
Environmental health factors associated with diarrhoeal diseases among under- five children in the Sebeta town of Ethiopia
}

\author{
Al Mohammed ${ }^{\mathrm{a}}$ and Li Zungu ${ }^{\mathrm{b} *}$ \\ a Medical and Health Services Department, Ethiopian Airlines, Addis Ababa, Ethiopia \\ ${ }^{b}$ Department of Health Studies, University of South Africa, Pretoria, South Africa \\ *Corresponding author, email: zunguli@unisa.ac.za
}

The aim of this study was to assess and explore household environmental health factors associated with the occurrence of diarrhoea experienced by children under five years of age in Sebeta town of Ethiopia. A cross-sectional study, using stratified random sampling was used to conduct the research. A total of 477 households' mothers/caregivers had participated in the study. The study showed that the prevalence of childhood diarrhoea was $9.9 \%$. A number of risk factors including demographic variables, water and hygienic practices, and knowledge of risk factors showed significant association with childhood diarrhoea on bivariate analysis. The multivariate analysis showed that four variables were protective factors for childhood diarrhoea, including the type of toilet facility (AOR: $0.37 ; 95 \% \mathrm{Cl} 0.16-0.87 ; p=0.023$ ), availability of specific hand-washing places (AOR: $0.40 ; 95 \% \mathrm{Cl}$ $0.18-0.90 ; p=0.026$ ), availability of hand-washing facilities (AOR: $0.20 ; 95 \% \mathrm{Cl} 0.06-0.70 ; p=0.012$ ) and mothers' knowledge on diarrhoea causation (AOR: $3.09 ; 95 \% \mathrm{Cl} 1.24-7.68 ; p=0.015$ ). The study, thus, recommends that effective measures to curtail prevalence of diarrhoea in urban contexts should be substantially increased by enhancing protective factors such as urban sanitation promotion programmes with emphasis on accelerating universal access to improved sanitation and hand-washing facilities, together with efforts in promoting proper hygiene behaviours.

Keywords: childhood, diarrhoea, environmental health factors, Ethiopia, Sebeta town, under-five children

\begin{abstract}
Introduction
Diarrhoeal diseases are major public health problems, especially in children in developing countries. ${ }^{1}$ Globally, diarrhoea remains the second most common cause of death among children under five years of age. ${ }^{2}$ There are an estimated 1.7 billion cases of diarrhoea with an average of 2.9 episodes/child/year, and an estimated 1.87 million deaths among children under five years of age. $^{3}$
\end{abstract}

More than $40 \%$ of the global burden of disease attributed to environmental factors falls on children below five years of age, who account for only about $10 \%$ of the world's population. ${ }^{4}$ Lack of safe water, sanitation and hygiene may account for as much as $88 \%$ of the disease burden due to diarrhoea. ${ }^{5}$ For example, and a well-known fact, most of the cases of diarrhoea worldwide are the result of faecal-oral contamination. Water supply, sanitation and hygiene are one of the top ten proven preventive interventions for morbidity and mortality of children under five years of age. ${ }^{6}$

The 2005 Ethiopian Demographic and Health Survey showed that the prevalence of under-five childhood diarrhoea in the two-week period was 18\% in Ethiopia.7 A 2011 Demographic and Health Survey also showed that $13 \%$ of children under the age of five had diarrhoea, in the two-week period before the survey. ${ }^{8}$ According to data sources from the World Health Organization and United Nations Children's Fund Joint Monitoring Programme for Water Supply and Sanitation, only $44 \%$ of the general population in Ethiopia has access to safe drinking water supplies. A further $79 \%$ of the population do not have access to improved sanitation facilities. ${ }^{9}$ There is ample evidence that access to adequate and safe water and sanitation can influence the current levels of child mortality and, therefore, these major determinants must be addressed in developing sustainable preventive interventions. ${ }^{10}$

To effectively prevent childhood diarrhoea, it is imperative that the important risk factors associated with diarrhoea in communities be identified through research. With these situations, this study aimed to assess and explore the association between household environmental health risk factors and the occurrence of diarrhoea among children under five years of age in an urban setting of Sebeta town in Ethiopia.

\section{Methods}

\section{Study design and setting}

A descriptive, cross-sectional design was used to conduct the study among households of Sebeta town from October to November 2013. The setting for this study, Sebeta town, is located in Oromiya region in Ethiopia. The town is 25 kilometres to the Southwest of Addis Ababa. Sebeta town is administratively divided into eight kebeles (local administrative unit below district), ${ }^{11}$ with a population of more than a 100000 people. ${ }^{12}$

\section{Sampling methods}

A two-stage stratified random sampling method was used to select the samples in which the population was first divided into relevant strata (subgroups). Firstly, the kebeles was considered as strata and all eight kebeles of the town were included in the study. Thereafter, all the lists of households with under-five children in each kebele (community) which were registered by the kebele health post were used as the sampling frame for the random selection of sampling units. A proportional size allocation method was employed to determine the number of 
study subjects in each kebele. In the second stage of sampling, from each stratum (kebele), households with under-five children were selected using the simple random sampling technique by means of a table of random numbers.

\section{Sample size}

The sample size for this study was determined using the statistical formula of $N=Z^{2} P(1-P) / d^{2}$ for estimation of single population proportion in prevalence study. ${ }^{13}$ In the formula, where $n$ was the required sample size, $P$ was the proportion of diarrhoea (assumed prevalence of diarrhoea of $17 \%), Z$ was the standard score corresponding to $95 \%$ confidence level (and is thus equal to 1.96) and $d$ was the margin of error (estimated at 5\%). With a design effect of 2 for the multistage nature of stratified sampling and a non-response rate of $10 \%$, accordingly, the sample size for the study was 477 households' mothers/caregivers with underfive children.

\section{Inclusion and exclusion criteria}

The inclusion sampling criteria for this study were:

(i) Household's mother/caregiver having a child who had not yet completed his or her 60th month. In cases, where there were more than one under-five child in the same household, the youngest child was selected; and,

(ii) Households that were registered as having under-five children by the kebele health post.

The exclusion sampling criteria for the research were:

(i) Institutions (such as offices, hotels, etc.) other than households; and,

(ii) Households that did not have child/children under five years of age and were not registered as having under-five children by the kebele health post.

\section{Ethical considerations}

The Health Studies Higher Degrees Committee of the department of Health studies at the University of South Africa (UNISA) granted the ethical clearance certificate to conduct the research. Institutional consent was also sought from the government institution in Ethiopia. Permission was obtained from the Oromiya Regional Health Bureau to conduct the study in Sebeta town of Ethiopia. Voluntary informed consent was obtained from all the study participants.

\section{Data collection}

Two types of structured data collection methods were used in the study. These were structured interview and structured observational methods. The data collection tool which was employed for household interview and observation methods is the structured interview schedule (questionnaire). A structured data collection tool was developed after carrying out a literature review and was mainly adapted from the publications of World Health Organization and United Nations Children's Fund, ${ }^{14}$ Environmental Health Project, ${ }^{15}$ Hygiene Improvement Project, ${ }^{16}$ and United Nations Children's Fund. ${ }^{17}$

The type of question in the interview schedule was based on the two types of variables of the study, namely dependent (outcome) and independent (explanatory) variables. The occurrence of childhood diarrhoea in an under-five child within the last two weeks preceding the study interview was considered to be the dependent (outcome) variable. The outcome measure, diarrhoea in under-five children, was based on mothers' response (yes or no) to a question on whether a particular child under 60 months of age had experienced diarrhoea during the two weeks prior to the interview. This was measured by asking mothers with children under the age of 5 years to provide information about the history of diarrhoea for the two weeks prior to the interview. Diarrhoea is defined as three or more loose or liquid stools passed in a 24 hour period. ${ }^{15}$ Environmental health factors were considered to be the independent variables. Thus, the questions of the structured data collection tool were focused on sociodemographic data, household environmental health conditions and childhood diarrhoea.

The data collection tool was initially developed in the English language and then translated to Afan Oromo, which is the local language of the study area. The structured data collection tool was pretested in the same study area where the main data collection was performed. The pretest was carried out in 10\% (47 households) of the total sample size of the study.

The data collection from the randomly selected households of Sebeta town was conducted by a field data collection team, which consisted of the principal researcher and the field data collectors. The field data collectors were urban health extension workers of the kebele health posts in Sebeta town. The data collectors were trained for one day on data collection methods and the interview/observation methodology. Twenty-nine data collectors were grouped into eight teams as per the eight kebeles of Sebeta town to gather data from the households. The principal researcher was responsible for overall coordination of the whole data collection process and checking of the data quality during the field data collection period.

\section{Data analysis}

Data were coded and entered into a computer using EPI Info 7.0 and analysed using SPSS version 20.0 statistical software. The summary results of the descriptive statistics were presented using tables and graphs. In analysing data, both bivariate and multivariate analyses were employed using SPSS software programme to identify the determinants of childhood diarrhoea. Bivariate analysis was conducted using chi-square test of independence or Fisher's exact test. Multivariate analyses were performed using the binary logistic regression to estimate the association between the dependent variable and independent variables. All the independent variables that were found significant with a $p$ value less than 0.25 in the bivariate analysis were entered into the regression model, and a backward stepwise (likelihood ratio) method was used for the multivariate analysis. The results of the multivariate analysis were presented with an adjusted odds ratio (AOR) with $95 \%$ confidence intervals $(\mathrm{Cl})$ and $p$ values. In all the analyses, the test was two-sided and a $p$ value less than or equal 0.05 was considered statistically significant.

\section{Results}

\section{Socio-economic and demographic data of the study households}

All the household respondents, from a total of 477 households that were randomly selected for the study in Sebeta town of Ethiopia, participated in the interview, thus resulting in a response rate of $100 \%$. The largest proportion (93.3\%) of the interview respondents comprised mothers of the under-five children, whereas $6.7 \%$ were female caregivers who were at least 
18 years of age. The majority of the respondents (92.9\%) were from urban areas, while $7.1 \%$ were from rural areas (town peripheral areas within town boundary but with rural characteristics).

The results of the study show that the mean age of the mothers was 28.6 years. The majority of the mothers were between the age of 20 and 29 years (64.6\%). The majority of the mothers (91\%) were married. According to the results of the study, $26.4 \%$ mothers were illiterate (cannot read and write) and $73.6 \%$ were literate. The majority of household heads (86\%) were literate and $14 \%$ were illiterate. The results of the study regarding the mothers' types of job show that $54.5 \%$ mothers were housewives and $16.8 \%$ were private traders. The mean for the number of under-five children in the households was 1.3 , and $72.1 \%$ of mothers had one under-five child. The majority of households (81.1\%) had more than three household members, and the mean household family size of the study population was 4.7. The majority of households (65.4\%) had a family monthly income of less than or equal to 1000 Ethiopian Birr (ETB). About three-fifths of the houses were privately owned (61.4\%), and over half $(55.1 \%)$ of the house floors were made of earthen floor. More than half $(56.2 \%)$ of the households had three separate rooms or less, and the mean for the number of separate house rooms held by the study population was 3.3. Table 1 displays the households' socioeconomic and demographic characteristics.

\section{Environmental health conditions}

The percentage of the population with access to improved piped water was $96.6 \%$. The mean per person per day for water consumption in the households was 2.4 litres. Five out of nine households (54.3\%) had treated their drinking water at home. The majority of households $(92.7 \%)$ had toilet facilities that members of the household routinely used, and less than onethird of households (29.4\%) had used an antiquated toilet facility. Regarding children's stool disposal practices, the majority of the households (81.1\%) used a proper disposal method (contained). Two-thirds of the households (67.9\%) had used improper wastewater disposal methods. Nearly three-fifths of the households (58.1\%) used a proper solid waste disposal method. The study indicates that over one-half of the households (55.1\%) had specific places for handwashing and an overwhelming majority of the households (93.1\%) had handwashing devices. About three-fifths of the households (61.2\%) had water for washing their hands at the specific handwashing places, and over four-fifths of the respondents (84.5\%) had good knowledge on at least three causes of diarrhoea. Table 2 presents the household environmental health characteristics.

\section{Under-fives' demographic and health characteristics}

The results of the study showed that the mean age of the underfive children was 25.6 months. About one-third of the children $(32.1 \%)$ were in the age group of $36-59$ months, and $29.8 \%$ ranged from 24-35 months of age. Three-fifths of the under-five children $(59.5 \%)$ were males, while two-fifths of the under-five children (40.5\%) were females.

The prevalence rate of diarrhoea among under-five children in the two weeks proceeding the interview day was $9.9 \%$ (Table 3 ). Furthermore, all of the children that had diarrhoea (47, 100\%) were found to have suffered from the illness for a duration of less than 14 days (acute diarrhoea), with a mean of 3.3 days.

\section{Bivariate analysis of factors associated with childhood diarrhoea}

In the bivariate analysis, using the chi-squared and Fischer's exact tests, a number of risk factors appeared to be significantly associated with childhood diarrhoea. The identified risk factors were: area of residence $\left(\chi^{2}(1, N=477)=7.71, p=0.01\right)$, household head's education $\left(\chi^{2}(1, N=477)=3.78, p=0.05\right)$, household's level of water treatment $\left(\chi^{2}(1, N=477)=5.38, p=0.02\right)$, mother's/ caregiver's washing practices with soap on washing a child's bottom after defecation $\left(\chi^{2}(1, N=477)=4.02, p=0.05\right)$, availability of specific places for handwashing $\left(\chi^{2}(1, N=477)=5.98, p=0.02\right)$, availability of handwashing devices (facility) $\left(\chi^{2}(1, N=477)=\right.$ $16.69, p=0.001)$, availability of water for handwashing at the specific handwashing places $\left(\chi^{2}(1, N=477)=7.65, p=0.006\right)$, the mother's/caregiver's knowledge on hand-washing with soap before feeding children $\left(\chi^{2}(1, N=477)=3.69, p=0.05\right)$ and the mother's/caregiver's knowledge on at least three causes of diarrhoea $\left(\chi^{2}(1, N=477)=5.87, p=0.02\right)$ (Table 4).

\section{Multivariate analysis of factors associated with childhood diarrhoea}

The bivariate analysis was conducted using chi-square and Fisher's exact tests to identify the risk factors of childhood diarrhoea; however, any possible confounding factors were not controlled at this level. Multivariate analysis was performed using the binary logistic regression by backward stepwise method with a likelihood ratio approach in order to identify the risk factors that are independently associated with diarrhoea while controlling for confounding variables. Only independent variables that were significantly associated with childhood diarrhoea at a $p$ value less than 0.25 in the bivariate analysis using chi-square test and Fisher's exact test were included in the multivariable analysis. The Hosmer-Lemeshow test indicates chisquare value with a $p>0.05\left(\chi^{2}=3.338,8\right.$ degrees of freedom, $p=0.91)$ which signifies that the overall model fit is good.

The regression model indicated that four variables were found to be independent protective factors for childhood diarrhoea in the expected direction. These protective factors were:

- The type of toilet facility used was significantly associated with diarrhoea (AOR: $0.37 ; 95 \% \mathrm{Cl} 0.16-0.87 ; p=0.023$ ).

- The availability of specific places for handwashing had a significant association with childhood diarrhoea (AOR: 0.40; 95\% Cl 0.18-0.90; $p=0.026$ ).

- Childhood diarrhoea was significantly associated with the availability of handwashing devices (facility) (AOR: 0.20; 95\% Cl 0.06-0.70; $p=0.012$ ).

- Mother's knowledge on the causes of diarrhoea was significantly associated with diarrhoea in children (AOR: 3.09; 95\% Cl 1.24-7.68; $p=0.015$ ).

Table 5 provides a summary of the binary logistic regression results.

\section{Discussion}

This study examined household environmental health factors associated with the occurrence of childhood diarrhoea of Sebeta town in Ethiopia. The results indicated that the prevalence of diarrhoea was $9.9 \%$ in under-five children in the previous two weeks preceding the interview. This rate was less prevalent compared to study findings by the Ethiopian Demographic and Health Survey of 2011, in which national childhood diarrhoea 
Table 1: Household socio-economic and demographic characteristics $(N=477)$

\begin{tabular}{|c|c|c|}
\hline Characteristic $(N=477)$ & Frequency & Percentage \\
\hline \multicolumn{3}{|l|}{ Area of residence } \\
\hline Urban & 443 & 92.9 \\
\hline Rural & 34 & 7.1 \\
\hline \multicolumn{3}{|l|}{ Mothers age } \\
\hline $20-29$ & 308 & 64.6 \\
\hline $30-39$ & 159 & 33.3 \\
\hline $40-49$ & 10 & 2.1 \\
\hline \multicolumn{3}{|l|}{ Mothers education } \\
\hline Illiterate & 126 & 26.4 \\
\hline Literate & 351 & 73.6 \\
\hline \multicolumn{3}{|l|}{ Household head education } \\
\hline Illiterate & 67 & 14.0 \\
\hline Literate & 410 & 86.0 \\
\hline \multicolumn{3}{|l|}{ Main job of the mother } \\
\hline Private trade (merchant) & 80 & 16.8 \\
\hline Housewife & 260 & 54.5 \\
\hline Others & 137 & 28.8 \\
\hline \multicolumn{3}{|l|}{ Number of under-five children } \\
\hline 1 & 344 & 72.1 \\
\hline$>1$ & 133 & 27.9 \\
\hline \multicolumn{3}{|c|}{ Number of persons in households } \\
\hline$\leq 3$ & 90 & 18.9 \\
\hline$>3$ & 387 & 81.1 \\
\hline \multicolumn{3}{|c|}{ Family monthly income in Ethiopian Birr } \\
\hline$\leq 1,000$ & 312 & 65.4 \\
\hline$>1,000$ & 165 & 34.6 \\
\hline \multicolumn{3}{|l|}{ Type of house ownership } \\
\hline Private owned & 293 & 61.4 \\
\hline Rented & 184 & 38.6 \\
\hline \multicolumn{3}{|c|}{ Number of separate house rooms } \\
\hline$\leq 3$ & 268 & 56.2 \\
\hline$>3$ & 209 & 43.8 \\
\hline \multicolumn{3}{|c|}{ Main material of the floor of the house } \\
\hline Earthen floor & 263 & 55.1 \\
\hline Non-earthen floor & 214 & 44.9 \\
\hline
\end{tabular}

*1 US Dollar (USD) equals 20.7 Ethiopian Birr (ETB) on July 20, 2015. ${ }^{18}$

prevalence rate was recorded at $13 \%$ for the country, $11.3 \%$ for the Oromiya region, and $11 \%$ for the urban areas of the country. ${ }^{9}$ The data for this study were collected during the month of November, which is a dry season in the study setting of Ethiopia. Conducting the study during a dry season might not reflect the diarrhoea prevalence rates during the rainy season. Other studies indicate that there is a relation between diarrhoeal illnesses and weather-related and climate-related events. ${ }^{19}$ In some studies, diarrhoea prevalence was found to be higher in the rainy season than in the dry season. ${ }^{20}$

Slightly over half of the study households (54.3\%) treated their drinking water at home, and the bivariate analysis of the study using chi-square test indicated that there was a statistical significance in the association between diarrhoea and householdbased drinking water treatment. However, after controlling the influence of other variables in the multivariate analysis, childhood diarrhoea and household-based drinking water treatment had no significant association. Similarly, a study conducted in Kenya found that none of the water treatment methods used by households had any association with diarrhoea. ${ }^{21}$ In contrast, a cross-sectional analytical study conducted in Tanzania showed that treating water with any method $(\mathrm{AOR}=0.49,95 \% \mathrm{Cl} 0.28-$ 0.84 ) and treating water by boiling ( $A O R=0.39,95 \% \mathrm{Cl} 0.2-0.7)$ were associated with reduced risk of diarrhoea. ${ }^{22}$

The type of toilet facility used showed no significant association with diarrhoeal disease in children when examined in the bivariate analysis. In the multivariate analysis, the type of toilet facility used was a significant protective factor for childhood diarrhoea; and, showed a significant negative effect $(A O R=0.37$; $95 \% \mathrm{Cl} 0.16-0.87 ; p=0.023)$. This means that children of 
Table 2: Environmental health conditions of the study households $(N=477)$

\begin{tabular}{|c|c|c|}
\hline Characteristic $(N=477)$ & Frequency & Percentage \\
\hline \multicolumn{3}{|l|}{ Main source of drinking water } \\
\hline Piped water & 461 & 96.6 \\
\hline Non-piped water & 16 & 3.3 \\
\hline \multicolumn{3}{|l|}{ Household-level water treatment } \\
\hline Yes & 259 & 54.3 \\
\hline No & 218 & 45.7 \\
\hline \multicolumn{3}{|c|}{ Availability of a toilet facility that members of the household usually use } \\
\hline Available & 442 & 92.7 \\
\hline Not available & 35 & 7.3 \\
\hline \multicolumn{3}{|l|}{ Type of toilet facility used } \\
\hline Improved & 337 & 70.6 \\
\hline Unimproved & 140 & 29.4 \\
\hline \multicolumn{3}{|l|}{ Stool disposal methods } \\
\hline Contained (proper disposal) & 387 & 81.1 \\
\hline Uncontained (improper disposal) & 90 & 18.8 \\
\hline \multicolumn{3}{|l|}{ Type of domestic wastewater disposal method } \\
\hline Proper disposal of wastewater & 153 & 32.1 \\
\hline Improper disposal of wastewater & 324 & 67.9 \\
\hline \multicolumn{3}{|l|}{ Type of household solid waste disposal method } \\
\hline Proper disposal & 277 & 58.1 \\
\hline Improper disposal & 200 & 41.9 \\
\hline \multicolumn{3}{|l|}{ Availability of specific place for handwashing } \\
\hline Available & 263 & 55.1 \\
\hline Not available & 214 & 44.9 \\
\hline \multicolumn{3}{|c|}{ Availability of handwashing device (water tap or local water holding receptacle, pail with dipper, kettle, jug, basin or sink) } \\
\hline Available & 444 & 93.1 \\
\hline Not available & 33 & 6.9 \\
\hline \multicolumn{3}{|c|}{ Availability of water for handwashing at the specific handwashing place } \\
\hline Available & 292 & 61.2 \\
\hline Not available & 185 & 38.8 \\
\hline \multicolumn{3}{|c|}{ Mothers knowledge of at least three causes of diarrhoea } \\
\hline Poor (mentioned none or 1-2) & 74 & 15.5 \\
\hline Good (mentioned more than two or 3-12) & 403 & 84.5 \\
\hline
\end{tabular}

Table 3: Children's demographic and health characteristics $(N=477)$

\begin{tabular}{|c|c|c|}
\hline Characteristic $(N=477)$ & Frequency & Percentage \\
\hline \multicolumn{3}{|l|}{ Age of child (months) } \\
\hline $0-6$ & 35 & 7.3 \\
\hline $7-11$ & 45 & 9.4 \\
\hline $12-23$ & 102 & 21.4 \\
\hline 24-35 & 142 & 29.8 \\
\hline \multicolumn{3}{|l|}{ Gender of child } \\
\hline Male & 284 & 59.5 \\
\hline Female & 193 & 40.5 \\
\hline \multicolumn{3}{|c|}{ Diarrhoea in under-five child within the last two weeks preceding the interview } \\
\hline Yes & 47 & 9.9 \\
\hline \multicolumn{3}{|l|}{ Duration of diarrhoea } \\
\hline$<14$ days (acute diarrhoea) & 477 & 100 \\
\hline$>14$ days (persistent diarrhoea) & - & - \\
\hline
\end{tabular}


Table 4: Risk factors for diarrhoea in children under the age of five years $(N=477)$

\begin{tabular}{|c|c|c|c|c|}
\hline \multirow[t]{2}{*}{ Characteristic $(N=477)$} & \multicolumn{2}{|c|}{$\begin{array}{l}\text { Diarrhoea in under- } \\
\text { five children }\end{array}$} & \multirow[t]{2}{*}{$\chi^{2}$} & \multirow[t]{2}{*}{$p$ value } \\
\hline & $\begin{array}{l}\text { Yes No. } \\
(\%)\end{array}$ & $\begin{array}{l}\text { No No. } \\
(\%)\end{array}$ & & \\
\hline \multicolumn{5}{|l|}{ Area of residence } \\
\hline Urban & $39(8.8)$ & 404 (91.2) & 7.71 & $0.01^{*, * *}$ \\
\hline Rural & $8(23.5)$ & $26(76.5)$ & & \\
\hline \multicolumn{5}{|l|}{ Household head education } \\
\hline Illiterate & $11(16.4)$ & $56(83.6)$ & 3.78 & $0.05^{*}$ \\
\hline Literate & $36(8.8)$ & $374(91.2)$ & & \\
\hline \multicolumn{5}{|l|}{ Household-level water treatment } \\
\hline Yes & $18(6.9)$ & $241(93.1)$ & 5.38 & $0.02^{*}$ \\
\hline No & $29(13.3)$ & $189(86.7)$ & & \\
\hline \multicolumn{5}{|c|}{$\begin{array}{l}\text { Mother's/caregiver's washing practices with soap during the previous } 24 \mathrm{~h} \text { on washing a child's bottom after } \\
\text { defecation }\end{array}$} \\
\hline Yes & $12(6.1)$ & $184(93.9)$ & 4.02 & $0.05^{*}$ \\
\hline No & $30(11.6)$ & $228(88.4)$ & & \\
\hline \multicolumn{5}{|c|}{ Availability of specific places for handwashing } \\
\hline Available & $18(6.8)$ & $245(93.2)$ & 5.98 & $0.02^{*}$ \\
\hline Not available & $29(13.6)$ & $185(86.4)$ & & \\
\hline \multicolumn{5}{|l|}{ Availability of handwashing devices } \\
\hline Available & $37(8.3)$ & $407(91.7)$ & 16.69 & $0.001^{* * * *}$ \\
\hline Not available & $10(30.3)$ & $23(69.7)$ & & \\
\hline \multicolumn{5}{|c|}{ Availability of water for handwashing at the specific handwashing places } \\
\hline Available & $20(6.8)$ & $272(93.2)$ & 7.65 & $0.006^{*}$ \\
\hline Not available & $27(14.6)$ & $158(85.4)$ & & \\
\hline \multicolumn{5}{|c|}{ Mother's/caregiver's knowledge on handwashing with soap before feeding children } \\
\hline No & $30(12.4)$ & $211(87.6)$ & 3.69 & $0.05^{*}$ \\
\hline Yes & $17(7.2)$ & $219(92.8)$ & & \\
\hline \multicolumn{5}{|c|}{ Mothers' knowledge of at least three causes of diarrhoea } \\
\hline Poor (mentioned none or 1 to 2 ) & $13(17.6)$ & $61(82.4)$ & 5.87 & $0.02^{*}$ \\
\hline Good (mentioned more than two) & $34(8.4)$ & $369(91.6)$ & & \\
\hline
\end{tabular}

*Statistically significant with $p$ value $\leq 0.05$.

**Fisher's exact test.

Table 5: Multivariate analysis of factors associated with diarrhoea among under-five year children

\begin{tabular}{|c|c|c|c|c|}
\hline Characteristics & Crude OR $(95 \% \mathrm{Cl})$ & Coefficient & Adjusted OR ( $95 \% \mathrm{CI})$ & $P$ value \\
\hline Time to obtain drinking water (round trip) $(\leq 30 \mathrm{~min} />30 \mathrm{~min})$ & $1.95(0.71-5.79)$ & 1.270 & $3.56(0.79-15.98)$ & 0.097 \\
\hline Type of toilet facility used (Improved/Unimproved) & $0.64(0.33-1.25)$ & -0.997 & $0.37(0.16-0.87)$ & $0.023^{*}$ \\
\hline Type of toilet ownership (Private toilet/Shared toilet) & $3.65(0.83-22.44)$ & 1.452 & $4.27(0.90-20.25)$ & 0.067 \\
\hline Mothers' practices on hand-washing with soap before feeding children (No/Yes) & $1.87(0.88-3.98)$ & 0.800 & $2.23(0.98-5.05)$ & 0.056 \\
\hline Availability of specific places for handwashing (Available/Not available) & $0.47(0.24-0.91)$ & -0.910 & $0.40(0.18-0.90)$ & $0.026^{*}$ \\
\hline Availability of handwashing devices (facility) (Available/Not available) & $0.21(0.09-0.51)$ & -1.597 & $0.20(0.06-0.70)$ & $0.012^{*}$ \\
\hline Mothers' knowledge on at least three causes of diarrhoea (Poor/Good) & $2.31(1.09-4.86)$ & 1.127 & $3.09(1.24-7.68)$ & $0.015^{*}$ \\
\hline
\end{tabular}

*Statistically significant with $p$ value $\leq 0.05$.

households with improved toilet facilities had a lower prevalence of diarrhoeal disease than those children whose households used unimproved toilets. The latter is indicative of the importance of the availability of improved toilet facilities and its impact in reducing childhood diarrhoea.
Furthermore, the bivariate analysis showed that, except washing a child's bottom after defecating which was statistically significant with childhood diarrhoea $(p=0.05)$, all variables of mothers' washing practices with soap, including washing hands and her body, washing the children's hands, washing clothes and washing the children's body did not show any significant association with childhood diarrhoea. After controlling for other 
variables in the multivariate analysis, the results showed that washing a child's bottom after defecating was not significantly associated with diarrhoea occurrence. Even though washing hands with soap did not show a significant relationship with diarrhoea in this study, the importance of using soap to rid the hands of microbiological contamination, and its association with reducing the risk of diarrhoea, have been demonstrated consistently in the past in several studies. ${ }^{23}$

Studies have shown that the existence of a designated place for handwashing is a good approximation of actual handwashing practice, and closely related to diarrhoeal disease prevalence. ${ }^{24}$ In the current study, the bivariate analysis revealed a significant association between the availability of specific places for handwashing and diarrhoea in under-five children. The significant association was retained even after controlling for all the other variables in the multivariate analysis. Children from households with a specific place for hand-washing were 0.40 times less likely to have diarrhoea compared to those from households that did not have specific places for handwashing $(A O R=0.40 ; 95 \% \mathrm{CI}$ $0.18-0.90 ; p=0.026$ ). Studies in developing countries have found that a handwashing facility where soap and water are colocated in one place for handwashing at key times, are important determinants of good handwashing practice with soap habits. ${ }^{25}$

For the hygiene of a household to improve, the primary caretaker must have easy access to a place to wash his or her hands, which has water and soap within easy reach. Access means that the members of the household can wash their hands when needed. One of the elements in the proper handwashing place is to have a handwashing device allowing for unassisted handwashing (e.g. tap, pail, water container, clay pot, handwashing sink, or tippy tap). ${ }^{15}$ The results of this study in the bivariate analysis showed a significant difference in childhood diarrhoeal disease among households that had handwashing devices compared with those that did not have such devices. Even after controlling for other variables, the difference in the risk of diarrhoea remained significant. Thus, children from households that had handwashing facilities were 0.20 times less likely to have diarrhoea as compared to those that did not have handwashing facilities ( $A O R=0.20$; $95 \% \mathrm{Cl} 0.06-0.70 ; p=0.012$ ).

In addition, the results for the bivariate analysis showed that mothers' knowledge of at least three causes of diarrhoeal diseases was a significant protective factor for childhood diarrhoea. Furthermore, the significant association was maintained even after controlling for the effects of other variables in the multivariate analysis. The results showed that children whose households had poor knowledge on at least three causes of diarrhoea were 3.09 times more likely to develop diarrhoea than those that had a good knowledge (AOR $=3.09 ; 95 \% \mathrm{Cl} 1.24-7.68$; $p=0.015)$.

Similarly, a cross-sectional survey conducted as a baseline survey to provide data for monitoring the impact and effectiveness of a water supply and sanitation intervention showed that responses to four of the survey questions reflecting the knowledge of disease causation and prevention were associated on their own with significant differences in diarrhoea prevalence among the index children. ${ }^{24}$ Children whose caretakers thought that washing the children's hands, supervising what they eat, washing fruits and vegetables, and washing kitchen utensils are important preventive actions had a lower prevalence of diarrhoea. All such practices were protective against diarrhoea, reducing risk by about $40 \%$ when compared with children of mothers who thought that these practices were unimportant in diarrhoea prevention.

Limitations - The study units (households) that were included in the study were from the municipal communities of Sebeta town in Oromiya Regional State. Other towns in Ethiopia were not included in this study. Research results, therefore, were limited to this particular town and may not be generalised to other towns in the country. Furthermore, as the study was not a trend or follow-up type of research, it did not consider seasonal differences in the occurrences of diarrhoea.

\section{Conclusions}

The findings identified important environmental determinants that contribute to the occurrence of diarrhoea in under-five children of Sebeta town in Ethiopia. Both facilities (technologies) and behavioural aspects of environmental health act more notably as determinants of childhood diarrhoeal disease. The findings conclude that childhood diarrhoea has a number of environmental determinants, particularly environmental health risk factors associated with lack of improved sanitation and handwashing facilities and poor knowledge on diarrhoea causation. This clearly indicates the importance of environmental health as a determinant of child health. The importance of providing priority to protective factors for childhood diarrhoea such as the promotion of the availability and use of improved sanitation technologies and good hygiene practices, particularly focusing on the availability and use of handwashing designated places and hygienic hand-washing facilities; and, ensuring mothers'/caregivers' knowledge about the causes of diarrhoea is fundamental. This implies that hygiene promotion programmes should give priority to protective factors such as the safe disposal of excreta, the adequate washing of hands and increasing mothers'/caregivers' knowledge on the causes of diarrhoea to encourage appropriate hygiene practices. These actions need to be addressed in the planning and implementation of urban environmental health, sanitation and hygiene promotion programmes for the prevention of childhood diarrhoea. There is a need for effective measures to curtail the prevalence of diarrhoea among children by enhancing universal access to improved sanitation, household hygiene technologies for handwashing and promoting proper hygiene behaviours through hygiene promotion.

Acknowledgements - The authors thank those study participants who volunteered to participate in the research as well as the Urban Health Extension Workers of the health posts of Sebeta town who participated in the interviews.

\section{Conflict of interest - The authors declare none.}

\section{References}

1. Scrimgeour AG, Lukaski HC. Zinc and diarrheal disease: current status and future perspectives. Curr Opin Clin Nutr Metab Care. 2008;11:711-7.

2. World Health Organization, United Nations Children's Fund. Diarrhoea: why children are still dying and what can be done. Geneva: World Health Organization (WHO) \& United Nations Children's Fund (UNICEF); 2009.

3. Brown J, Cairncross S, Ensink JHJ. Water, sanitation, hygiene and enteric infections in children. Arch Dis Child. 2013;98:629-34.

4. World Bank. Environmental health and child survival: epidemiology, economics, experiences. Washington, DC: The World Bank; 2008.

5. Kleinau E, Post M, Rosensweig F. Advancing hygiene improvement for diarrhoea prevention: lessons learned. (Strategic report 10) Washington, DC: United States Agency for International Development (USAID) Environmental Health Project (EHP); 2004. 
6. Environmental Health Project. The hygiene improvement framework: a comprehensive approach for preventing childhood diarrhoea. Washington, DC: USAID Environmental Health Project (EHP); 2004.

7. Central Statistical Agency \& ORC Macro. Ethiopia demographic and health survey 2005. Addis Ababa \& Calverton: Central Statistical Agency (CSA) of Ethiopia and ORC Macro; 2006.

8. Central Statistical Agency \& ICF International. Ethiopia demographic and health survey 2011. Addis Ababa \& Calverton: Central Statistical Agency (CSA) of Ethiopia and ICF International; 2012.

9. World Health Organization \& United Nations Children's Fund. Progress on drinking water and sanitation: 2012 update. Geneva: World Health Organization (WHO) and United Nations Children's Fund (UNICEF); 2012.

10. Ministry of Health of Ethiopia. National strategy for child survival in Ethiopia. Addis Ababa: Ministry of Health; 2005.

11. Sebeta Town Administration. Sebeta town magazine. Sebeta: Sebeta Town Administration; 2012.

12. Office Sebeta Town Health. Annual plan of 2011/12 of Sebeta Town Health Office. Sebeta: Sebeta Town Health Office; 2012.

13. Naing L, Winn T, Rusli BN. Practical issues in calculating the sample size for prevalence studies. Arch Orofac Sci. 2006;1:9-14.

14. World Health Organization \& United Nations Children's Fund. Core questions on drinking-water and sanitation for household surveys. Geneva: World Health Organization (WHO) and United Nations Children's Fund (UNICEF); 2006.

15. Kleinau E, Pyle DF. Assessing hygiene improvement: guidelines for household and community levels. (Strategic report 8). Washington, DC: United States Agency for International Development (USAID) Environmental Health Project (EHP); 2004.

16. Hygiene Improvement Project. Access and behavioural outcome indicators for water, sanitation and hygiene. Washington, DC: United States Agency for International Development (USAID) Hygiene Improvement Project; 2010.

17. United Nations Children's Fund. Multiple indicator cluster survey manual MICS4: 2012 [cited 2013 May 8]. Available from: http://www. childinfo.org/mics4_manual.html
18. Commercial Bank of Ethiopia. Currency rate table: 2014 [cited 2014 February 17]. Available from: http://www.combanketh.et/More/ CurrencyRate.aspx

19. Agustina R, Sari TP, Satroamidjojo S, et al. Association of food-hygiene practices and diarrhoea prevalence among Indonesian young children from low socioeconomic urban areas. BMC Public Health. 2013;13(1):1-12.

20. Hung BV. The most common causes of and risk factors for diarrhoea among children less than five years of age admitted to Dong Anh Hospital, Hanoi, Northern Vietnam [Master of Philosophy in International Community Health]. Oslo: University of Oslo; 2006.

21. Karambu S, Matiru V, Kiptoo M, et al. Characterization and factors associated with diarrhoeal diseases caused by enteric bacterial pathogens among children aged five years and below attending Igembe District Hospital, Kenya. Pan Afr Med J. 2013;16(37):1-8.

22. Kakulu RK. Diarrhoea among under-five children and household water treatment and safe storage factors in Mkuranga district Tanzania [Masters thesis]. Dar es Salaam, Tanzania: Muhimbili University of Health and Allied Sciences; 2012.

23. Saadé C, Bateman M, Bendahmane DB. The story of a successful public-private partnership in Central America: hand-washing for diarrhoeal disease prevention. BASICS, the Environmental Health Project, the United Nations Children's Fund, the United States Agency for International Development, and The World Bank; 2001.

24. Kelly $\mathrm{P}$, Khanfir $\mathrm{H}$, David PH, et al. Environmental and behavioural risk factors for diarrhoeal diseases in childhood: a survey in two towns in Morocco. Washington, DC: United States Agency for International Development (USAID) Environmental Health Project (EHP); 1999.

25. Jenkins MW, Anand AR, Revell G, et al. Opportunities to improve domestic hygiene practices through new enabling products: a study of hand-washing practices and equipment in rural Cambodia. International Health 2013;5(4):295-301.

Received: 23-07-2015 Accepted: 13-01-2016 